\title{
Devorah Dimant
}

\section{History, Ideology and Bible Interpretation in the Dead Sea Scrolls}

\section{Collected Studies}

[Geschichte, Weltanschauung und Bibeldeutung in den Schriftrollen vom Toten Meer. Gesammelte Studien.]

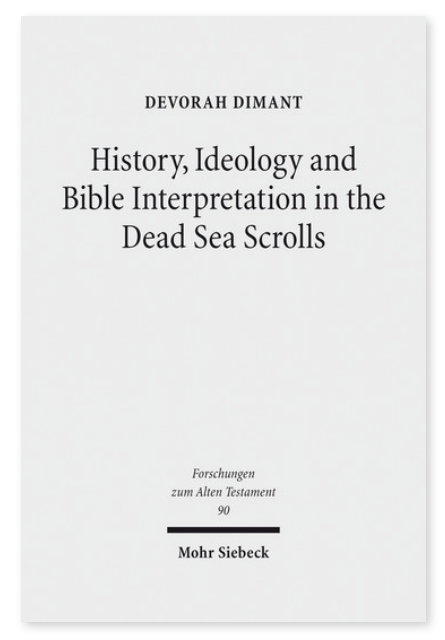

2014. XV, 610 Seiten. FAT 90

ISBN 978-3-16-152851-4

DOI 10.1628/978-3-16-152851-4

eBook PDF $214,00 €$

ISBN 978-3-16-151021-2

Leinen $214,00 €$
Veröffentlicht auf Englisch.

Devorah Dimant versammelt in diesem Band siebenundzwanzig vollständig überarbeitete und teilweise neu geschriebene Aufsätze zu den verschiedenen Aspekten der Schriftrollen vom Toten Meer, die sie in den letzten drei Jahrzehnten veröffentlicht hat. Ein einleitender Aufsatz, der speziell für diesen Band verfasst wurde, gibt einen Überblick über den gegenwärtigen Stand der Forschung zu den Schriftrollen. Die Autorin behandelt zentrale Themen der Schriftrollen vom Toten Meer und reflektiert die rasche Ausbreitung und den Wandel der Forschungsperspektive auf die Sammlung in den Jahren nach ihrer vollständigen Veröffentlichung. Zu den behandelten Themen zählen auch Form und Inhalt der Sammlung als Ganzes, die spezielle Literatur der Gemeinde, der diese Sammlung gehörte, die aramäischen Texte und die apokryphen und pseudepigraphischen Werke, die darin entdeckt wurden. Der Band enthält auch Untersuchungen zu spezifischen Themen wie der Geschichte der Gemeinde, zu der die Schriftrollen gehörten, ihr Selbstbild sowie bestimmte Deutungen von biblischen Verheißungen und ihr Zeitverständnis.

\section{Devorah Dimant}

Born 1939; studied Religion and Literature of Ancient Judaism; 1974 PhD; Professor emerita for Biblical Studies at the University of Haifa, Israel.
Jetzt bestellen:

https://mohrsiebeck.com/buch/history-ideology-and-bible-interpretation-in-the-dead-sea-scrolls-9783161528514?no_cache=1 order@mohrsiebeck.com

Telefon: +49 (0)7071-923-17

Telefax: +49 (0)7071-51104 